\title{
ANALISIS RESIKO SOIL TRANSMITTED HELMINT DI SEKOLAH DASAR DI KECAMATAN PADAHERANG, KABUPATEN CIAMIS, JAWA BARAT
}

\author{
Siti Uswatun Chasanah, Ariana Sumekar \\ School of Health Sciences Wira Husada Yogyakarta \\ Babarsari Street, Glendongan, Tambak Bayan, Depok, Sleman \\ Email: uswcha.pit@gmail.com
}

\begin{abstract}
Background: Based on quantity of target at elementry school student's in helmint elemination program on Health Department Ciamis 2007, prevalence in elementry school at Raja Desa Village are $15 \%$. it's happen because not health beahaviour and poor sanitation. This research aims is to know a prevalence and risk factor about soil transmitted helminth in elementry school at Padaherang Subdistict.

Method: This research conducted with cross sectional study, using simple random sampling and analysis with Pearson Correlation. Sample size in this research is 364 students from one until four class at 5 elementry school in Padaherang Subdistrict. Feces have been examined with flooting methode using $\mathrm{NaCl}$. This methode can found eggs worm and what spesies they are, but can not examined grade or level of infection. Resembling with collecting feces sample at field, respondence questioned about they're knowledge, behaviour and environment in home and school.

Result: A student's positive helminth was 110 from 364, so a prevalence in student at elementry school are 30,21\%. From 110 student's, 58 student infected by Ascaris lumbricoides, 47 student infected Trichuris trichiura and 5 student are multiple infection by both of them. Only knowledge is relationship with infection, behavior, school environment and house environment is not any relationship.

Conclusion: Knowledge is a basic element from behavior, promotion with health education is very important to up level of health. But, it's not easy, need long time programme to made it succesfuul. Cooperation with all element and sector is needed to elimination this disease.
\end{abstract}

Keywords: Ascaris lumbricoides, prevalence, soil transmitted helminth, elementary school, Trichuris trichiura

\footnotetext{
Abstrak

Latar Belakang: Berdasarkan jumlah sasaran siswa sekolah dasar program kecacingan tahun 2007 Dinas Kesehatan Ciamis menyebutkan bahwa prevalensi infeksi cacing usus pada siswa sekolah dasar di Desa Rajadesa sebesar $15 \%$. Hal ini terjadi karena beberapa perilaku tidak sehat yang masih dilakukan dan sanitasi yang buruk. Penelitian ini bertujuan untuk mengetahui faktor risiko dan prevalensi kecacingan pada anak-anak SD di Kecamatan Padaherang, Kabupaten Ciamis, Jawa Barat.

Metode Penelitian: Penelitian ini dilakukan dengan studi cross sectional, pengambilan sampel dengan simple random sampling dan dianalisis dengan menggunakan korelasi Pearson. Jumlah Sampel dalam penelitian ini adalah 364 siswa yang terdiri dari kelas 1 hingga kelas 4 di 5 Sekolah Dasar di Kecamatan Padaherang. Tinja yang telah diperiksa menggunakan $\mathrm{NaCldengan} \mathrm{metode} \mathrm{acak.} \mathrm{Metode} \mathrm{ini} \mathrm{dapat} \mathrm{menemukan} \mathrm{telur} \mathrm{cacing} \mathrm{dan} \mathrm{jenis} \mathrm{cacingnya,}$ tetapi tidak dapat diperiksa kadar atau tingkat infeksi. Selain dengan mengumpulkan sampel tinja di lapangan, responden juga ditanya tentang pengetahuan, perilaku dan lingkungan rumah dan sekolah.

Hasil Penelitian: Dari 364 sampel yang diperiksa 110 sampel positif kecacingan sehingga prevalensi kecacingan pada anak SD di Kecamatan Padaherang sebesar 30,21\%. Dari 110 siswa, 58 siswa yang terinfeksi oleh cacing Ascaris lumbricoides, 47 siswa yang terinfeksi
} 
Trichuris trichiura dan 5 mahasiswa yang beberapa infeksi oleh keduanya. Hanya pengetahuan yang berhubungan dengan infeksi kecacingan, sedangkan variabel perilaku, lingkungan sekolah dan lingkungan rumah tidak terdapat hubungan.

Kesimpulan: Pengetahuan adalah dasar dari perilaku, promosi dengan pendidikan kesehatan sangat penting untuk meniingkatkan kesehatan. Tetapi, itu tidak mudah, butuh waktu lama untuk mensukseskan program tersebut. Kerjasama dengan semua elemen dan sektor sangat diperlukan.

Kata Kunci: Ascaris lumbriocoides, prevalensi, soil transmitted helminth, sekolah dasar, Trichuris trichiura

\section{Pendahuluan}

Infeksi Soil transmitted helminthes (STH) atau kecacingan masih merupakan penyakit yang terabaikan di Indonesia (neglected diseases). STH merupakan penyakit yang banyak mengakibatkan morbiditas dibandingkan mortalitas. Walaupun terapinya cukup mudah dan murah tetapi penyakit ini masih banyak ditemukan di Indonesia diduga karena rendahnya pengetahuan orang tua dan sanitasi lingkungan yang kurang baik. Rendahnya perhatian orang tua mengenai kecacingan dikarenakan penyakit ini tidak akan menyebabkan gangguan yang berarti bagi anaknya.

Kecacingan sangat terkait erat dengan kondisi lingkungan dan budaya perilaku sehat masyarakat, khususnya anak-anak, karena pada usia tersebut intensitas interaksi dengan lingkungan (tanah) semakin besar, sehingga meningkatkan pula risiko terinfeksi. Di Indonesia penyakit ini dapat berkembang dengan baik karena didukung dengan kelambaban yang cukup tinggi sehingga perkembangan cacing dapat berjalan dengan maksimal. Ada empat cacing yang tergolong soil transmitted helminthes yang biasanya menginfeksi manusia yaitu, Ascaris lumbricoides, Trichuris trichiura, Necator americanus, dan Ancylostoma duodenale. Ke empat jenis cacing ini mempunyai prevalensi yang cukup tinggi di Indonesia, baik didaerah urban atau rural.

Prevalensi infeksi cacing usus di Sekolah Dasar di Kecamatan Bulak, Surabaya sebesar 14,6\% yang terdiri dari Ascariasis (10,4\%)dan Trichiuriasis (4,2\%). Penelitian yang dilakukan ${ }^{1}$ di Bangunjiwo, Bantul, DIY mendapatkan prevalensi tertinggi pada anak-anak pra-sekolah $63,8 \%$ dan infeksi oleh Trichuris trichiura tertinggi pada penduduk dengan tingkat pendidikan SD sampai kelas tiga yaitu 93,9.

Berdasarkan jumlah sasaran siswa sekolah dasar program kecacingan tahun 2007 Dinas Kesehatan Ciamis menyebutkan bahwa prevalensi infeksi cacing usus pada siswa sekolah dasar di Desa Rajadesa sebesar $15 \%$. Hasil pemeriksaan dilakukan oleh petugas Laboratorium Kesehatan Daerah. Hal ini terjadi karena beberapa perilaku tidak sehat yang masih dilakukan, diantaranya yaitu buang air besar di tempat yang tidak semestinya (empang), tidak cuci tangan setelah buang air besar dan cuci tangan tidak dengan sabun hanya air saja. Menurut data dari Laporan Program Kesehatan Lingkungan Puskesmas Sindangwangi Kecamatan Padaherang Kabupaten Ciamis Jawa Barat tahun 2008, cakupan jamban keluarga di Desa Sukanagara adalah 99,99\%, 39,10\% diantaranya memenuhi syarat, 28,75\% tidak memenuhi syarat dan $32,14 \%$ tidak memiliki jamban keluarga. Jumlah rumah dengan sarana air bersih yang memenuhi syarat sebesar 50,48\%, 37,47\% tidak memenuhi syarat dan $12,05 \%$ tidak memiliki sarana air bersih. Diantara empat desa lainnya jumlah rumah yang tergolong sehat di Desa Sukanagara sangat rendah yaitu sebesar $17,19 \%$.

Adanya infeksi cacing dalam usus manusia menimbulkan efek yang berbedabeda, tapi tidak akan menyebabkan kematian. Gangguan kesehatan atau efek dari kecacingan dapat berupa hanya gatal-gatal, anoreksia, lemah, lesu, daya konsentrasi berkurang, tidur tertanggu hingga anemia. Apabila infeksi terus berlanjut dengan kuantitas cacing yang cukup besar kemungkinan akan terjadi malnutrisi dan anemia 
mikrositik hipokromik. Anemia dan malnutrisi yang berat pada usia pertumbuhan (anakanak) akan dapat menyebabkan gangguan perkembangan mental dan fisik anak tersebut. Dampak ini lah yang paling menonjol dalam permasalahan kecacingan.

Pemberantasan penyakit kecacingan merupakan suatu langkah dan usaha jangka panjang yang terus berkesinambungan. Pendekatan secara kuratif tidak akan dapat berjalan dengan maksimal apabila tidak ditunjang dengan kesadaran akan potensi risiko terinfeksi cacing, sehingga perlu dilakukan suatu penelitian yang berkesinambungan untuk mengetahui prevalensi kecacingan disuatu daerah dan faktor risiko yang menyertainya.Berdasarkan latar belakang tersebut, dalam penelitian ini akan dikaji tentang hubungan perilaku anak sekolah dasar serta gambaran sanitasi rumah kaitannya dengan kejadian kecacingan.

\section{Metode Penelitian}

Penelitian ini merupakan penelitian observasional analitik dengan menggunakan studi bedah-lintang (cross-sectional study). Pada penelitian ini faktor risiko dan kasus diukur secara bersamaan, sehingga kelemahannya tidak dapat menentukan apakah sebab mendahului akibat atau akibat yang mendahului sebab, sehingga tidak dapat dilihat dengan jelas pengaruh antar keduanya. Dalam penelitian ini akan dilihat prevalensi, hubungan antar variabel bebas dengan varibel terikat dan besarnya risiko. Populasi dalam penelitian ini adalah seluruh anak-anak di sekolah dasar di Kecamatan Padaherang, Kabupaten Ciamis, Jawa Barat, sedangkan sampel penelitian adalah anak-anak sekolah dasar dari kelas 1 hingga kelas 4 di seluruh SD (5 SD) di Kecamatan Padaherang. Anak-anak tersebut akan diambil tinjanya kemudian dilakukan wawancara dan pengamatan. Sampel tinja anak-anak tersebut akan diperiksa dengan menggunakan pemeriksaan secara langsung dengan menggunakan teknik pengapungan. Besar sampel direncanakan sebesar 400 sampel yang merupakan jumlah siswa dari kelas satu hingga kelas 4 namun pada saat penelitian hanya mendapatkan 364 sampel yang bersedia mengembalikan pot sampel pemeriksaan tinja, masing-masing kelas rata-rata terdiri dari 20 siswa, pengambilan sampel dilakukan dengan simple random sampling. Dibantu oleh wali kelas, peneliti membagikan pot untuk penyimpanan tinja yang kemudian diberikan formalin cair untuk pengawetan sampel yang akan diperiksa di laboratorium STIKES Wira Husada.

\section{Hasil Penelitian Dan Pembahasan}

\section{A. Hasil Penelitian}

\section{a. Kondisi Demografis}

Kecamatan Padaherang sebelumnya termasuk kedalam wilayah kerja Kabupaten Ciamis, tetapi dengan adanya pemekaran kabupaten baru, dimana wilayah Pangandaran yang pada awalnya termasuk wilayah Kabupaten Ciamis memisahkan diri menjadi Kabupaten baru yang bernama Kabupaten Pangandaran, walaupun sampai tahun ini masih belum mempunyai susunan pemerintahan yang tetap karena masih dalam masa percobaan apakah kabupaten ini bisa berdiri sendiri atau tidak.

Kecamatan Padaherang, Pangandaran, Jawa Barat, Indonesia. Terdiri dari 4 Dusun, yaitu Dusun Padaherang, Dusun Sindangherang, Dusun Burujul, dan Dusun Sukarenah. Luas wilayah Kecamatan Padaherang sekitar 638,425 $\mathrm{Ha}$, dengan jumlah penduduk sekitar 6.453 jiwa, yang terdiri dari: laki-laki = 3.177 dan perempuan $=3.276$ jiwa. Kecamatan Padaherang berbatasan langsung dengan Desa Karangpawitan di sebelah Timur, Desa Kedungwuluh di sebelah Utara dan Barat, dan Desa Karangsari di sebelah Selatan. 


\section{b. Sosial Masyarakat}

Masyarakat pra sejahtera dan sejahtera I di Desa Padaherang Kecamatan Padaherang Kabupaten Ciamis berdasarkan hasil pendapatan keluarga tahun 2008 adalah: Pra Sejahtera $=329 \mathrm{KK}$, Sejahtera $=205 \mathrm{KK}$, jumlah jiwa 410. Masyarakat desa Padaherang adalah masyarakat yang sangat baik yang selalu taat dan patuh kepada peraturan baik peraturan adat, agama, maupun peraturan pemerintah. Namun demikian, pada akhir-akhir ini budaya gotong royong hampir terkikis dengan masuknya budaya-budaya dari luar desa Padaherang dan kemajuan teknologi. Bulan Bakti Gotong Royong adalah momentum yang baik dan tepat untuk membentengi masyarakat desa Padaherang dari pengaruh-pengaruh luar yang merugikan masyarakat desa Padaherang.

\section{c. Analisis univariat}

364 sampel yang diperiksa, 110 sampel positif kecacingan sehingga prevalensi kecacingan pada Anak SD di Kecamatan Padaherang sebesar 30,21\%. Dari 110 sampel yang positif, 58 positif Ascaris lumbricoides; 47 positif Trichuris trichiura; 5 infeksi campuran (Ascaris lumbricoides dan Trichuris trichiura).

Hasil penelitian ini semakin menegaskan bahwa infeksi soil transmmited helmith tidak hanya bersifat infeksi tunggal tetapi sangat memungkinkan sekali untuk terjadinya multiple infection. Hal ini bisa terjadi karena dalam siklus hidupnya kedua jenis cacing ini memerlukan tanah untuk perkembangbiakan telurnya agar bisa menjadi telur yang infektif.Infeksi campuran yang terjadi menunjukkan bahwa terjadi infeksi yang berulang pada anak tersebut.

\section{d. Analisis bivariat} berikut.

Untuk mengetahui hasil analisis bivariat dapat dilihat dari Tabel 1

Tabel 1. Rekapitulasi Nilai RP dan P-Value Tiap Variabel

\begin{tabular}{|c|c|c|c|c|}
\hline \multirow{2}{*}{ Variabel } & \multicolumn{2}{|c|}{ Penyakit Kecacingan } & \multirow{2}{*}{ RP (Cl 95\%) } & \multirow{2}{*}{ P-Value } \\
\hline & Sakit & Sehat & & \\
\hline Pengetahuan Anak & & & \multirow{3}{*}{$\begin{array}{c}1,89 \\
(1,38-2,59)\end{array}$} & \multirow{3}{*}{0,000} \\
\hline Kurang & 63 & 88 & & \\
\hline Baik & 47 & 164 & & \\
\hline Perilaku Anak & & & \multirow{3}{*}{$\begin{array}{c}0,93 \\
(0,69-1,32)\end{array}$} & \multirow{3}{*}{0,90} \\
\hline Kurang & 67 & 158 & & \\
\hline Baik & 43 & 96 & & \\
\hline Kondisi Lingkungan Sekolah & & & \multirow{3}{*}{$\begin{array}{c}0,88 \\
(0,44-1,60)\end{array}$} & \multirow{3}{*}{0,72} \\
\hline Kurang & 15 & 40 & & \\
\hline Baik & 95 & 214 & & \\
\hline Kondisi Lingkungan Rumah & & & \multirow{3}{*}{$\begin{array}{c}0,91 \\
(0,65-1,27)\end{array}$} & \multirow{3}{*}{0,69} \\
\hline Kurang & 75 & 180 & & \\
\hline Baik & 35 & 74 & & \\
\hline
\end{tabular}

Sumber : data primer (2013)

Tabel 1 menunjukan bahwa dari empat variabel yang diteliti hanya variabel pengetahuan yang bermakna atau berhubungan secara statistik dengan nilai $P$ value 0,00 dan RP 1,89 yang berarti bahwa anak yang pengetahuannya masih kurang akan berisiko 1,89 kali lebih besar untuk terinfeksi kecacingan dibandingkan anak yang pengetahuannya baik. 
Tabel 1 tersebut menunjukkan bahwa penderita kecacingan pada anak SD di Kecamatan Padaherang lebih banyak yang berpengetahuan kurang baik (63 orang) dibandingkan dengan yang berpengetahuan baik (47 orang), sedangkan pada kelompok yang tidak terinfeksi lebih banyak yang berpengetahuan baik (164 orang) dibandingkan dengan yang pengetahuannya kurang (88 orang). Seperti diketahui bahwa hanya satu variabel yang bermakna sehingga dalam penelitian ini tidak dimungkinkan lagi untuk dilanjutkan hingga ke tahap analisis multivariat.

\section{B. Pembahasan}

\section{a. Pengetahuan}

Analisis di atas menyatakan bahwa pengetahuan anak di SD di Kecamatan Padaherang sudah baik, dengan 58,51\% anak berpengetahuan baik, hasil ini masih lebih kecil dibandingkan dengan penelitian yang dilakukan Astutiningsih yang melakukan penelitian di SD Banteran I Ngaglik Sleman dengan $61,66 \%$ siswa yang berpengetahuan baik dan penelitian yang dilakukan Tumanggor ${ }^{2}$ di SD 030375 Kabupaten Dairi dengan 66,2\%. Pada penelitian lain terdapat perbedaan secara statistik, dan dalam penelitian ini pun ada perbedaan yang signifikan walaupun pengetahuan yang kurang baik mempunyai risiko 1,89 kali terinfeksi cacing. Hasil penelitian ini berbeda dengan penelitian yang dilakukan Widihapsari dan Fauiziah, yaitu tidak ada hubungan pengetahuan dengan terjadinya kecacingan. ${ }^{3}$

Empat penelitian yang pernah dilakukan sebelumnya pada tahun 1999, 2006, 2008 dan 2009, masing-masing menunjukkan hasil yang berbeda-beda, penelitian tahun 2006 dan 2008 menunjukkan adanya hubungan pengetahuan dengan kejadian kecacingan, sedangkan tahun 1999 dan 2009 tidak menunjukkan adanya perbedaan. Pengetahuan merupakan salah satu faktor yang secara teoritis berhubungan dengan berbagai macam tindakan atau perilaku yang dilakukan seseorang.

Pengetahuan merupakan hasil dari suatu proses pembelajaran yang diperoleh seseorang, baik dari lembaga formal maupun informal. Pengetahuan akan muncul ketika seseorang menggunakan akal budinya untuk mengenali benda atau kejadian tertentu yang belum pernah dilihat atau dirasakan sebelumnya, pengetahuan tersebut dipengaruhi oleh pendidikan, media dan informasi. Pengetahuan merupakan domain yang sangat penting untuk terbentuknya tindakan seseorang (overt behavior). ${ }^{4}$

Berdasarkan tingkatannya, pengetahuan dibagi menjadi enam tingkatan yaitu, know; comprehension; application; analysis; synthesis; evaluation. Ketidakbermaknaan hasil penelitian ini kemungkinan karena orang tua dan anak, pengetahuannya hanya sebatas "know". Know atau tahu diartikan sebagai mengingat suatu materi yang telah dipelajari sebelumnya. Termasuk ke dalam pengetahuan tingkatan ini adalah mengingat kembali terhadap suatu yang spesifik dari seluruh bahan yang dipelajari atau rangsangan yang telah diterima. Oleh sebab itu "know" ini merupakan tingkat pengetahuan yang paling rendah. ${ }^{4}$

Penerapan pengetahuan mengenai hal-hal yang berhubungan dengan masalah kesehatan, khususnya mengenai gangguan yang dialami, apabila gangguan kesehatan tersebut terjadi secara teratur di dalam suatu kelompok/komunitas tertentu, maka setiap orang di dalam kelompok/komunitas tersebut dapat menghimpun pengetahuan tentang gangguan kesehatan yang mungkin dapat terjadinya gangguan kesehatan dalam hal ini kecacingan. 


\section{b. Perilaku}

Hasil penelitian ini tidak sejalan dengan penelitian yang dilakukan Sofiana.Pada penelitian Sofiana terdapat hubungan perilaku higiene perseorangan dengan infeksi kecacingan. ${ }^{5}$ Namun, penelitian ini sejalan dengan penelitian yang dilakukan oleh Hidayat yang menunjukkan bahwa tidak ada hubungan yang bermakna antara personal higiene dengan prevalensi kecacingan dan intensitas kecacingan pada murid SD di Kota Mataram.

Higiene perseorangan bukan merupakan faktor risiko yang berhubungan langsung dengan infeksi kecacingan, hal tersebut antara lain dipengaruhi adanya pemeriksaan higiene anak minimal satu kali dalam seminggu, menghukum anak yang tidak menggunakan alas kaki disekolah, dan menghukum anak yang berkuku panjang, materi pelajaran tentang kecacingan pada saat jam Penjaskes, mengaktifkan kegiatan UKS dan dokter kecil.

\section{c. Kondisi lingkungan sekolah}

Berdasarkan hasil penelitian tidak terdapat hubungan yang bermakna antara kondisi/sanitasi lingkungan sekolah dengan terjadinya kecacingan pada anak SD di Kecamatan Padaherang. Tidak adanya hubungan variabel ini kemungkinan disebabkan pihak sekolah dapat mengendalikan aspek-aspek sanitasi di sekolah dengan cukup baik.Hal ini sesuai dengan teori yang dikemukakan Riyadi, bahwa mengendalikan lingkungan merupakan suatu usaha untuk menghilangkan atau sekurang-kurangnya menguasai faktor-faktor lingkungan yang dapat menimbulkan penyakit. Menurut Achmad dalam Gazali bahwa penyakit kecacingan merupakan salah satu penyakit yang berbasis pada lingkungan, untuk mengendalikannya diperlukan usaha-usaha perbaikan sanitasi lingkungan yang diikuti dengan perbaikan perilaku hidup bersih dan sehat. $^{6}$

Sebagian halaman sekolah tidak lagi tanah yang berperan sebagai media penularan infeksi soil transmmited helmith. Siswa akan kontak dengan tanah secara langsung ketika mereka bermain atau berolah raga yang sewaktu ketika mengharuskan mereka untuk melepas alas kaki. Akan tetapi kondisi ini hanya berlangsung sementara karena setelah bermain atau berolah raga mereka akan kembali menggunakan sepatunya.

Berbeda dengan penelitian Istiqomah, menunjukkan bahwa ada hubungan yang bermakna antara sanitasi sekolah dengan penderita askariasis dan trikuriasis pada anak sekolah dasar di Kota Yogyakarta. Berarti bahwa semakin buruk kondisi lingkungan sekolah akan semakin banyak jumlah penderita askariasis dan trikhuriasis. ${ }^{7}$

\section{d. Kondisi lingkungan/sanitasi rumah}

Hasil penelitian ini menunjukkan bahwa tidak ada hubungan yang bermakna antara kondisi lingkungan/sanitasi rumah dengan terjadinya infeksi soil transmmited helmith pada anak sekolah dasar di Kecamatan Padaherang. Hasil penelitian ini berbeda dengan penelitian Sofiana dan Suhartono yang menunjukkan bahwa ada hubungan yang bermakna antara kondisi lingkungan/sanitasi rumah dengan terjadinya kecacingan.Namun, penelitian ini sejalan dengan penelitian yang dilakukan Hidayat dan Gazali. ${ }^{6}$

Lokasi penelitian sebagian besar rumah responden lantainya tidak lagi terbuat dari tanah tapi sudah di keramik atau paling tidak disemen/plester sehingga mengurangi risiko anak-anak dirumah tersebut untuk terinfeksi kecacingan. Tanah merupakan media yang sangat baik untuk perkembangbiakan cacing. 
Berdasarkan penelitian ini dapat disimpulkan bahwa yang berhubungan dengan terjadinya infeksi soil transmmited helmint adalah pengetahuan. Pada penelitian ini hanya menyajikan empat variabel bebas yaitu pengetahuan, perilaku, kondisi sekolah dan kondisi rumah. Faktor yang mempengaruhi terjadinya infeksi soil transmmited helmint tidak hanya empat variabel tersebut, sebenarnya masih banyak faktor lain yang dapat mempengaruhi terjadinya infeksi, seperti keadaan tanah, kelembaban, suhu, kepadatan lalat sebagai vektor, sikap, sosial-ekonomi dan yang lainnya. Namun, keterbatasan waktu dan luasnya wilayah juga menjadi pertimbangan lain yang mendasar bagi peneliti untuk tidak meneliti variabel yang lain.

Tidak sesuainya jumlah sampel yang dikemukan diproposal dengan laporan penelitian ini dikarenakan tidak semua anak mengembalikan pot tinja yang telah dibagikan. Ini disebabkan oleh berbagai hal seperti kecemasan atau ketakutan anak saat akan diambil tinjanya sehingga menyebabkan tinjanya tidak keluar, ada nya rasa jijik pada orang tua yang mengambil tinja anaknya dan belum tahunya manfaat dari pemeriksaan tinja ini. Walaupun hasil tinja yang didapatkan lebih dari $60 \%$ target tinja yang diinginkan.

\section{Simpulan dan Saran}

\section{A. Simpulan}

Kesimpulan yang dapat diambil dari penelitian ini adalah:

a. Prevalensi kecacingan pada anak sekolah dasar di Kecamatan Padaherang adalah $30,21 \%$.

b. Ada hubungan pengetahuan anak dengan terjadinya kecacingan pada anak SD di Kecamatan Padaherang.

\section{B. Saran}

Saran dari penelitian ini antara lain:

a. Bekerjasama dengan pihak terkait melakukan penyuluhan kesehatan kepada seluruh siswa

b. Bekerjasama dengan pihak terkait memberikan obat cacing kepada seluruh siswa

c. Bagi komite sekolah menyampaikan kepada orang tua siswa agar lebih memperhatikan kebersihan diri anak-anaknya

\section{Daftar Pustaka}

1. Fauziah, Shinta., Pengaruh Sanitasi Lingkungan Rumah, Pengetahuan, Sikap dan Higiene Perseorangan Terhadap Infeksi Kecacingan Pada Murid Sekolah Dasar, Skripsi, Fakultas Kesehatan Masyarakat, Universitas Airlangga, Surabaya, 2009.

2. Tumanggor, Anita H., Hubungan Perilaku Dan Higiene Siswa SD Negeri 030375 Dengan Infeksi Kecacingan Di Desa Juma Teguh Kabupaten Dairi, 2008. Diakses pada tanggal 10 Mei 2011 di http://repository.usu.ac.id/handle/123456789/16807.

3. Siregar, Bellina., Beberapa Faktor Yang Berhubungan Dengan Infeksi Kecacingan Yang Ditularkan Melalui Tanah Pada Murid SD Negeri 06 Kecamatan Pinggir Kabupaten Bengkalis, 2008. Diakses pada tanggal 10 Mei 2011 di http://repository.usu.ac.id/handle/123456789/16404.

4. Notoatmodjo, S., IImu Kesehatan Masyarakat; Prinsip - Prinsip Dasar, Edisi Ke-2, Rineka Cipta, Jakarta, 2003.

5. Sofiana, L., Hubungan Higiene Perorangan, Sanitasi Lingkungan Rumah dan Sekolah Dengan Infeksi Soil Transmitted Helminths Pada Anak Sekolah Dasar di Wilayah Kerja 
Puskesmas Kokap I Kabupaten Kulonprogo Yogyakarta, Tesis, Program Pasacasarjana Universitas Gadjah Mada, Yogyakarta, 2010.

6. Gazali, M., Hubungan Higiene Perseorangan Anak Sekolah Dasar dan Kondisi Kesehatan Lingkungan Rumah Dengan Terjadinya Kejadian Penyakit Kecacingan di Kecamatan Air Periukan Kabupaten Seluma Propinsi Bengkulu, Tesis, Program Pascasarjana Universitas Gadjah Mada, Yogyakarta, 2008.

7. Istiqomah, S, H., Analisis Kondisi Sanitasi Lingkungan Penderita Ascariasis dan Trichuriasis anak Sekolah Dasar di Kota Yogyakarta (Studi Kasus), Tesis, Program Pascasarjana Universitas Gadjah Mada, Yogyakarta, 2007. 